\title{
A phase I/lla study of adjuvant immunotherapy with tumour antigen-pulsed dendritic cells in patients with hepatocellular carcinoma
}

\begin{abstract}
Jeong-Hoon Lee ${ }^{1}$, Yoon Lee ${ }^{2,3}$, Minjong Lee ${ }^{1}$, Min Kyu Heo ${ }^{2}$, Jae-Sung Song ${ }^{2}$, Ki-Hwan Kim² ${ }^{2}$ Hyunah Lee ${ }^{4}$, Nam-Joon $\mathrm{Yi}^{5}$, Kwang-Woong Lee ${ }^{5}$, Kyung-Suk Suh ${ }^{5}$, Yong-Soo Bae ${ }^{\star 2,3}$ and Yoon Jun Kim ${ }^{\star}, 1$

${ }^{1}$ Department of Internal Medicine and Liver Research Institute, Seoul National University College of Medicine, 103 Daehak-ro, Jongno-gu, Seoul, 110-799, Republic of Korea; ${ }^{2}$ Division of DC Cancer Vaccine, JW CreaGene Research Institute, JW CreaGene Inc., Seongnam-si, Gyeonggi-do, 162-120, Republic of Korea; ${ }^{3}$ Department of Biological Science, Sungkyunkwan University, Suwon, Gyeonggi-do, 440-746, Republic of Korea; ${ }^{4}$ Cancer Center, Samsung Medical Center, School of Medicine, Sungkyunkwan University, Ilwon-dong, Kangnam-gu, Seoul, 135-710, Republic of Korea and ${ }^{5}$ Department of Surgery, Seoul National University College of Medicine, Seoul National University, Seoul, 110-799, Republic of Korea
\end{abstract}

Background: To date, no adjuvant treatment has been shown to have a clear benefit in patients with hepatocellular carcinoma (HCC). In this prospective phase I/lla study, we evaluated the safety and efficacy of adjuvant dendritic cell (DC) therapy in HCC patients who received primary treatment for HCC.

Methods: Twelve HCC patients who had no viable tumour after primary treatments were included. Dendritic cell vaccines pulsed with cytoplasmic transduction peptide-attached alpha-fetoprotein, glypican-3 and melanoma-associated antigen 1 recombinant fusion proteins were injected subcutaneously near to inguinal lymph nodes. Adverse effects, time to progression (TTP), and associated immune responses were evaluated after DC vaccination.

Results: Nine of 12 patients had no tumour recurrence up to 24 weeks after DC vaccination. Among a total of 144 adverse events, 129 events (89.6\%) were regarded as adverse drug reactions, all of which were grade 1 or 2 . The majority of patients showed enhanced anti-tumour immune responses after DC vaccination. Recurrence-free patients exhibited relatively stronger anti-tumour immune responses than patients who developed recurrence after DC vaccination, as evidenced by lymphocyte proliferation and IFN- $\gamma$ ELISPOT assays. The median time of TTP was 36.6 months in the DC-vaccination group and 11.8 months in the control group (hazard ratio, $0.41 ; 95 \%$ confidence interval, $0.18-0.95 ; P=0.0031$ by log-rank test).

Conclusions: Adjuvant DC vaccine for HCC was safe and well tolerated in phase I/lla study, and preliminary efficacy data are encouraging to warrant further clinical study in patients with HCC after primary treatments.

Globally, hepatocellular carcinoma (HCC) is the sixth most common malignancy and the third leading cause of cancer-related death. Surveillance programs for early detection of HCC in highrisk populations and improvement of therapeutic modalities have increased the likelihood of potentially curative treatment (Yuen et al, 2000; Bolondi et al, 2001). However, the long-term prognosis is still poor even after curative treatment due to the high frequency of recurrence in the remnant liver, which ranges up to $25 \%$ per

*Correspondence: Professor Y-S Bae; E-mail: ysbae04@skku.edu or ysbae@creagene.com or Professor YJ Kim; E-mail: yoonjun@snu.ac.kr

Received 16 July 2015; revised 7 November 2015; accepted 16 November 2015; published online 10 December 2015

(c) 2015 Cancer Research UK. All rights reserved 0007-0920/15 
year (Lai et al, 1995). This high recurrence rate has led to efforts to develop adjuvant therapies to reduce recurrence. A number of studies have explored adjuvant strategies; however, the benefit of any form of adjuvant therapy remains unclear (Schwartz et al, 2002; Samuel et al, 2009), and current scientific guidelines do not recommend adjuvant therapy in patients treated with resection or local ablation therapy (Bruix et al, 2011; European Association for The Study of The Liver, European Organisation for Research Treatment of Cancer, 2012; Verslype et al, 2012).

Dendritic cells (DCs) are professional antigen-presenting cells that have a critical role in the cell-mediated immune response by stimulating proliferation and activation of antigen-specific cytotoxic T cells (Banchereau and Steinman, 1998). Autologous DCs offer a practical basis for a tumour vaccine (den Brok et al, 2005), and adoptive immunotherapy using DC vaccine has been tested in clinical trials in various malignancies including prostate cancer, melanoma, renal cell carcinoma, and HCC (Nestle et al, 1998; Holt et al, 1999; Small et al, 2000; Lee et al, 2005; Butterfield et al, 2006; Palmer et al, 2009; Tada et al, 2012). Regarding HCC, a previous phase II study using intravenous vaccination with DCs ex vivo pulsed with HCC cell line (HepG2) lysate showed evidence of antitumour efficacy in some patients with advanced HCC (Palmer et al, 2009). A phase I/II study reported that strong T-cell responses against alpha-fetoprotein (AFP) were generated by immunisation with DCs pulsed with four AFP peptides as the immunogenic tumour-associated antigen (TAA) instead of tumour cell lysates in HCC patients. However, no clinical responses were observed in the treated patients (Butterfield et al, 2006).

In the present study, we used DC vaccines pulsed with multiple TAAs (i.e., AFP, glypican-3 (GPC-3) and melanoma-associated antigen 1 (MAGE-1)) to enhance the DC vaccine efficacy. Because no single antigen is ubiquitously expressed in HCC, we selected AFP, GPC-3, and MAGE-1 as target antigens for DC vaccine, which were most frequently detected in the tissue array of tumour tissues obtained from 412 Korean HCC patients at Seoul National University Hospital, Seoul, Korea (data not shown). In our previous collaborative study with a Japanese group, we demonstrated the safety and feasibility of the multiple TAA-pulsed DC vaccine in five patients with advanced $\mathrm{HCC}$ and observed a clinical benefit in one of these (Tada et al, 2012). Encouraged by these promising results, we aimed to evaluate the safety, efficacy, and immune activity of adjuvant immunotherapy using multiple TAApulsed DC vaccination in patients who were treated for HCC and had no evidence of residual tumour.

\section{PATIENTS AND METHODS}

Patient selection. Patients who had undergone treatment including surgical resection, radiofrequency ablation (RFA), percutaneous ethanol injection (PEI), or transarterial chemoembolization (TACE) as a treatment for HCC of clinical stage between I and III $_{C}$ according to the American Joint Committee on Cancer (AJCC) staging system (sixth edition) were eligible for this study (Greene, 2002). The diagnosis of HCC was made by histological examination or radiological imaging tests, mainly based on the guidelines of the American Association for the Study of Liver Diseases (Bruix et al, 2011). Detailed criteria for patient recruitment are described in Supplementary Methods.

Study oversight. This phase I/IIa clinical study was a prospective, open-labelled trial. The study was conducted at Seoul National University Hospital. All patients provided written informed consent before enrolment in this study. The study protocol and procedures were approved by the institutional review board at Seoul National University Hospital (H-0811-009-261). All methods and procedures associated with this study were conducted in accordance with the principles of the Declaration of Helsinki and local law. The study was designed by the sponsor (JW CreaGene, Inc., Seongnam-si, Gyeonggi-do, Korea) in conjunction with the principal academic investigators. Clinical Research Information is available on the website of the Korean Centers for Disease Control and Prevention, Ministry of Health and Welfare (http:// apps.who.int/trialsearch/Trial2.aspx?TrialID=KCT0000427).

Preparation of recombinant HCC antigens. As described previously (Tada et al, 2012), cDNAs encoding AFP, MAGE-1, and GPC-3 were cloned into the pCTP plasmid. These three antigens were expressed in E. coli BL21 and purified with a column of nickel-nitrilotriacetic acid $\left(\mathrm{Ni}^{+}{ }^{-} \mathrm{NTA}\right)$ chromatography (Qiagen, Hilden, Germany). Quality control of the antigens was performed to assure $>95 \%$ purity by SDS-PAGE and $<1.0 \mathrm{EU} \mu \mathrm{g}^{-1}$ endotoxin by Limulus amebocyte lysate test.

Autologous DC vaccine generation. Peripheral blood mononuclear cells (PBMCs) were obtained from the patients with HCC through leukapheresis at Seoul National University Hospital. Dendritic cells were generated from blood monocytes, as described previously (Kim et al, 2007), with minor modifications. DCs were prepared in a Good Manufacturing Practice-compliant facility at JWCreaGene, Inc. Peripheral blood mononuclear cells isolated by Ficoll-Paque PLUS (Amersham Biosciences, Uppsala, Sweden) density gradient centrifugation were resuspended in RPMI1640 medium (Lonza, Basel, Switzerland) supplemented with autologous heat-inactivated plasma, and then incubated in CellSTACK Culture Chambers (Corning, Corning, NY, USA). After $0.5-1 \mathrm{~h}$ incubation at $37^{\circ} \mathrm{C}$ in a $5 \% \mathrm{CO}_{2}$ incubator, non-adherent cells were removed by gentle washes. The adherent monocytes were cultured in X-VIVO15 (Lonza, East Rutherford, NJ, USA) supplemented with $100 \mathrm{ng} \mathrm{ml}^{-1}$ of granulocyte macrophagecolony-stimulating factor (JWCreaGene Inc.) and $300 \mathrm{ng} \mathrm{ml}^{-1}$ of interleukin (IL)-4 (JWCreaGene Inc.) for 5 days. On day 5, nonattached immature DCs were collected and pulsed with CTP-fused human AFP, MAGE-1, and GPC-3 recombinant proteins at a final concentration of $5 \mu \mathrm{g} \mathrm{ml}^{-1}$ each. Antigen-pulsed DCs were matured in the presence of cytokine cocktail, IL-6 (Peprotech, Rocky Hill, NJ, USA), IL-1 $\beta$ (Peprotech), tumour necrosis factor (TNF)- $\alpha$ (Peprotech), prostaglandin $\mathrm{E}_{2} \quad\left(\mathrm{PGE}_{2}\right.$; Sigma-Chemical Co., St Louis, MO, USA), interferon (IFN)- $\gamma$ (LG Life Science; Seoul, Korea), OK432 (Chugai Pharmaceutical Co., Tokyo, Japan), and poly I:C (Sigma) for 2 days. On day 7, the DCs were collected, washed, and resuspended in $2.0 \mathrm{ml}$ of cryopreserving solution containing 5\% dimethyl sulfoxide (Bioniche Pharma USA LLC, Rockford, IL, USA). Finally, fully equipped DCs were packed into a sterile glass vial $\left(5 \times 10^{7}\right.$ cells per vial), sealed with a snap-cap, and then stored at an ultralow freezer until administration.

Immunogenicity of DC vaccine in preclinical study. T-cell proliferation and cytotoxic $\mathrm{T}$ lymphocyte (CTL) induced in vitro by co-culture experiments with TAA-pulsed mDCs prepared from the PBMCs of healthy donors were assessed as described in Supplementary Methods.

Quality control of DC vaccine. Sterility, cell size and granularity, surface phenotype, cell viability, T-cell stimulation capacity, and cytokine production profiles of DC vaccine were evaluated according to the JWCreaGene Standard and Test Guidelines approved by the Korea Ministry of Food and Drug Safety. The detailed procedures are described in Supplementary Methods.

Treatment protocol. Patients who provided informed consent were screened within 4 weeks before the start of immunotherapy. 
Peripheral blood mononuclear cells were collected with leukapheresis 2 weeks before the first planned vaccination. TAA-pulsed DC vaccine was injected subcutaneously (s.c.) into the thigh near the inguinal lymph nodes. Toll-like receptor-7 (TLR-7) agonist (imiquimod: Mochida Pharmaceutical Co.; Tokyo, Japan) was applied topically around the injection site for 2 consecutive days before injection. Patients received six DC vaccines over 14 weeks (four treatments every 2 weeks and then two treatments every 4 weeks). Response was evaluated 4 weeks after the fourth vaccination (10 weeks after the first vaccination) and 4 weeks after the sixth vaccination (18 weeks after the first vaccination) (Figure 1A). Detailed flow of the study evaluating the tolerated dose (TD) is provided in Figure 1B. Dose-limiting toxicity (DLT) was defined as severe adverse drug reaction of grade 3 or 4 according to the National Cancer Institute's Common Terminology Criteria for Adverse Events (CTCAE), version 3.0. TAA-pulsed $\mathrm{DC}$ vaccine was designed to be administered at $5 \times 10^{7}$ cells per injection for the first three patients. If none of these three patients experienced DLT, then the next nine patients were planned to be treated at that dose, which was designated as TD. If one of the first three patients experienced DLT, three more patients were enroled at that dose level. If no more than one of six patients experienced DLT, the dose was defined as TD and the next nine patients were treated at the dose. If two of six patients experienced DLT, additional three patients were enroled and if none of the three patients experienced DLT, the dose was designated as TD. However, if $\geqslant 2$ patients of the first three patients, $\geqslant 3$ patients of the first six, or $\geqslant 3$ patients of the first nine patients experienced DLT, then the dose was reduced by $50 \%$ and TD finding trial was repeated. If TD was defined, toxicity evaluation was repeated until sample size (12-18 patients) was reached.

Outcomes and assessment. The primary outcomes were safety of DC vaccine and the induction of TAA-specific cellular immune response in patients with HCC. Adverse events classified and graded according to the CTCAE version 3.0 and World Health Organization-Adversary Reaction Terminology (WHO-ART) version 092 were assessed from the time the patient provided written informed consent until the end of the study or dropout/ withdrawal. TAA-specific cell-mediated immunity induced by DC vaccination was evaluated by interferon (IFN)- $\gamma$ enzyme-linked immunospot (ELISPOT) assay and lymphocyte proliferation assay with blood samples of weeks $0,4,10,18$, and 24 . The secondary outcomes including tumour recurrence and other status were evaluated as described in Supplementary Methods. In addition, 4-year follow-up study was performed, and time-to-progression (TTP) and recurrence-free survival (RFS) of the vaccinated patients were assessed in comparison with those of the historical controls during the same period.

Immune monitoring after vaccination. For immune monitoring after DC vaccination, antigen-specific IFN- $\gamma$ ELISPOT assay, lymphocyte proliferation assay in vitro and immunosuppressive cytokine analysis were performed with the patients' blood according to the Minimal Information about T-cell Assays (MIATA) guidelines (Britten et al, 2012) with some modifications as described in Supplementary Methods.

Statistics. The efficacy and outcomes were assessed according to the intention-to-treat principle. Missing values were imputed by last observation carried forward method. Changes in laboratory test results from baseline were compared by Wilcoxon signed-rank test. Repeated measures ANOVA was used to evaluate the changes in the results of IFN- $\gamma$ ELISPOT and lymphocyte proliferation assays. TTP and RFS were compared using a log-rank test. Statistical significance was set at $P<0.05$. The statistical analysis was performed using PASW Statistics version 19.0 (IBM, Chicago, IL, USA).

\section{RESULTS}

Patient characteristics. Between 16 March 2009 and 5 January 2010, 17 patients were screened. Among them, 12 met the eligibility criteria and were enroled in this study. Table 1 illustrates the baseline demographic and clinical characteristics. Ten patients $(83.3 \%)$ were male and the median age was 57 years (range, 45-71). All patients showed pre-immunisation positivity for delayed-type hypersensitivity response. Chronic hepatitis B was the predominant cause of underlying liver disease (83.3\%). Four patients underwent surgical resection, four RFA, two PEI, and two TACE, for HCC within 8 weeks before study enrolment. Six patients had a history of previous treatment for HCC. According to the AJCC staging system, eight patients had stage I, two had stage II, and two had stage $\mathrm{III}_{\mathrm{A}}$ HCC. When enroled, all 12 patients did not show any residual tumour on CT or MRI according to RECIST criteria a month after primary treatments. The first three patients were enroled between 16 March 2009 and 30 March 2009, and the next nine patients between 23 November 2009 and 5 January 2010. The date of the study end was 24 November 2010. Additional follow-up study for recurrence was assessed until the end of 2014 .

Characteristics of DC vaccine. In the preclinical study, we evaluated the immunogenicity TAA-pulsed mature DCs (mDCs) in vitro which were prepared from the PBMCs of three healthy donors. TAA-pulsed mDCs showed typical mDC phenotypes (Figure 2A). T-cell proliferation (Figure 2B) and CTL assay (Figure 2C) revealed that the TAA-pulsed mDCs were active enough to stimulate antigen-specific $\mathrm{CD} 8{ }^{+} \mathrm{T}$ cells and CTLs. Given this background, DC vaccine was generated from the 12 patients with HCC. The average yield of DC vaccine was about $3.9 \pm 2.0 \%$ of the initial amounts of PBMCs. Dendritic cell vaccines showed the typical features of $\mathrm{mDC}$ morphology under the microscope. All manufactured DC vaccines passed safety tests including sterility test, mycoplasma test, and endotoxin test (Table 2). The cell viability ranged from 75.4 to $89.8 \%$. According to flow cytometric analysis of the cell size and granularity, the population of DCs was $>80 \%$ of the cells, with a median value of 92.9\% (range, 84.4-97.8). Flow cytometry results confirmed that the DCs expressed high levels of major histocompatibility complex (MHC) class I (HLA-ABC), MHC class II (HLA-DR), and costimulatory molecules (CD86, CD80, CD40, and CD83). The analysis of lineage markers demonstrated that the contamination of B cells (CD19) and monocytes (CD14) was mostly $<2 \%$, except in one case $(\mathrm{CD} 14,8.4 \%)$. All of these quality controls are summarised in Table 2.

Dose and administration of DC vaccines. For the first three patients, $5 \times 10^{7}$ antigen-pulsed DCs were administered per injection, and there was no DLT. Thus, $5 \times 10^{7}$ cells per injection was defined as the TD. At the same dose, there was no DLT in the next nine patients. Although two patients (no. 07 and 09) experienced grade 3 haematologic adverse events (i.e., persistent leukopenia, neutropenia, and lymphopenia from the screening test in patient no. 07 and thrombocytopenia probably related to HCC progression in patient no. 09), the cases were assessed as no adverse drug reactions and thus no DLT. All patients received six injections of DC vaccine. DC vaccinations were administered as scheduled except for two patients (no. 07 and 09). Dose administration for the sixth dose was delayed by 19 days for no. 07 , and by 41 days for no.09 due to treatment for recurrence of HCC. 
A

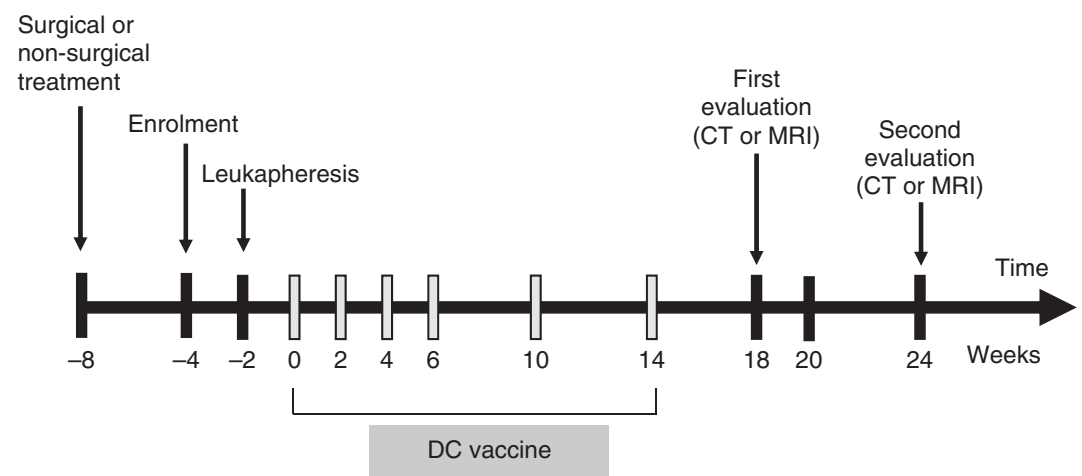

B

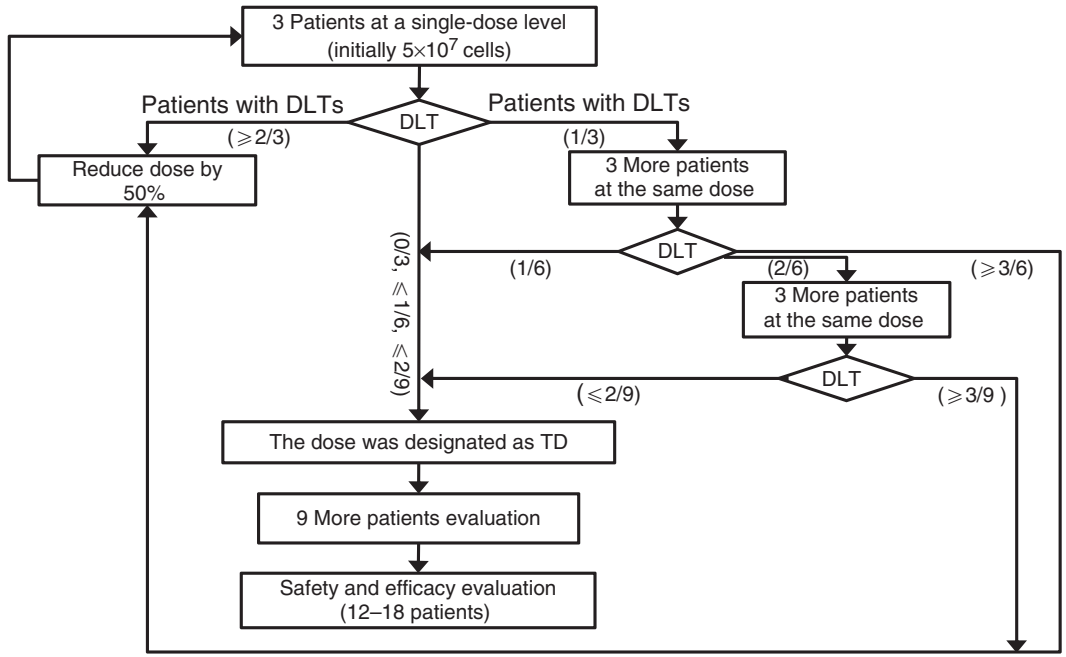

Figure 1. Study design. (A) Study design for vaccination and evaluation. CT= computed tomography; MRI= magnetic resonance imaging; DC = dendritic cell. (B) Flow chart for tolerated dose-finding study. DLT=dose-limiting toxicity; TD = tolerated dose.

\begin{tabular}{|c|c|c|c|c|c|c|c|c|c|c|}
\hline Patient no. & Age & Sex & ECOG $^{a}$ & $\begin{array}{l}\text { Risk } \\
\text { factor }\end{array}$ & $\mathrm{LC}^{\mathrm{b}}$ & $\begin{array}{l}\mathrm{HCC} \\
\text { stage }\end{array}$ & $\begin{array}{c}\text { Treatment records before DC } \\
\text { vaccination }\end{array}$ & $\begin{array}{l}\text { ChildPugh } \\
\text { score }\end{array}$ & $\begin{array}{c}\text { AFP } \\
\left(\mathrm{ng} \mathrm{ml}^{-1}\right)\end{array}$ & 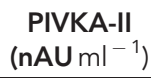 \\
\hline 01 & 63 & $\mathrm{~F}$ & 0 & HBV & Yes & 1 & R & 5 & 18.3 & 13 \\
\hline 02 & 61 & M & 0 & HBV & Yes & 1 & $R$ & 5 & 7.1 & 19 \\
\hline 03 & 53 & M & 0 & HBV & Yes & 1 & $\mathrm{R}$ & 5 & 6.1 & 19 \\
\hline 04 & 53 & M & 0 & HBV & Yes & II & $\mathrm{T} / \mathrm{T} / \mathrm{R} / \mathrm{T}$ & 5 & 7.0 & 14 \\
\hline 05 & 45 & M & 0 & HBV & Yes & I & P/P/Op & 5 & 5.4 & 16 \\
\hline 06 & 50 & M & 0 & HBV & Yes & II & $\mathrm{T} / \mathrm{P} / \mathrm{P} / \mathrm{P}$ & 5 & 6.5 & 18 \\
\hline 07 & 60 & M & 0 & HBV & Yes & I & $\mathrm{P} / \mathrm{T} / \mathrm{R}$ & 6 & 3.3 & 27 \\
\hline 08 & 66 & M & 0 & $\mathrm{U} / \mathrm{N}$ & Yes & I & Op & 5 & 2.9 & 21 \\
\hline 09 & 52 & M & 0 & HBV & Yes & $\mathrm{II}_{\mathrm{A}}$ & $\mathrm{T} / \mathrm{T} / \mathrm{T} / \mathrm{T} / \mathrm{T}$ & 5 & 5470.0 & 2040 \\
\hline 10 & 57 & $M$ & 0 & HBV & No & $\mathrm{III}_{\mathrm{A}}$ & Op & 5 & 2.6 & 30 \\
\hline 11 & 57 & $F$ & 0 & HBV & Yes & 1 & Op & 5 & 6.6 & 9 \\
\hline 12 & 71 & M & 0 & Alcohol & Yes & 1 & $\mathrm{~T} / \mathrm{T} / \mathrm{T} / \mathrm{T} / \mathrm{T} / \mathrm{P}$ & 6 & 12.0 & 18 \\
\hline
\end{tabular}

Safety evaluation. Table 3 summarises all adverse events. During the treatment period, a total of 144 adverse events occurred among the 12 patients, and there were no grade 3 or 4 adverse events except for the aforementioned grade 3 haematologic adverse events in two patients. Approximately $90 \%$ of adverse events (129 of 144) were assessed as adverse drug reactions. The most common adverse drug reactions were injection site pain (12 patients), fever (8 patients), myalgia (7 patients), headache (5 patients), and fatigue (4 patients) (Table 3 ). However, most adverse drug reactions were self-limited and resolved within 1 or 2 days. Four patients experienced a total of serious adverse events including HCC progression (five events in three patients (no. 07, 09, and 12)) and 
A
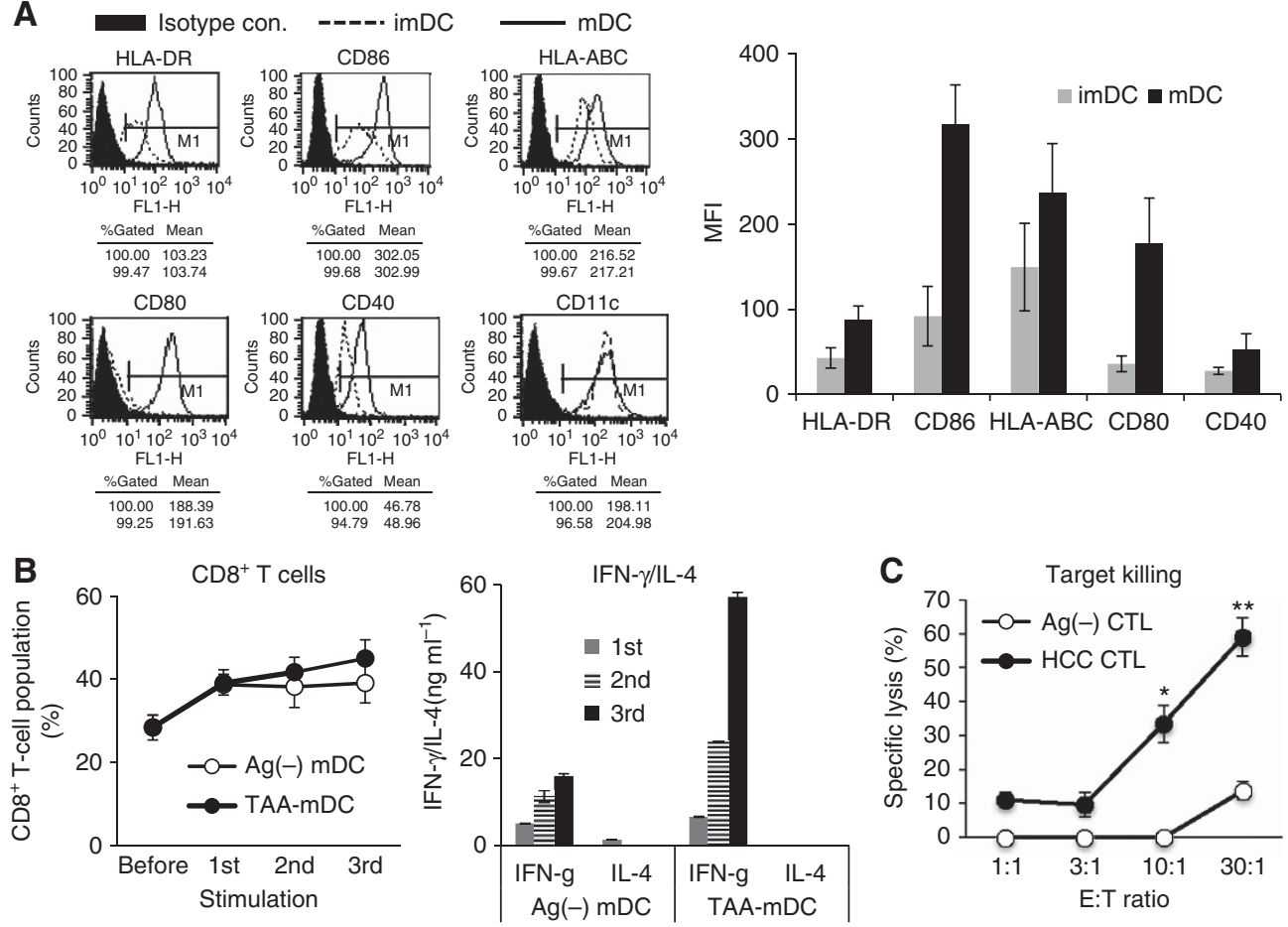

Figure 2. Surface phenotypes and T-cell stimulation capacity of TAA-pulsed mDCs in the preclinical study, which were performed as described in the Supplementary Method. (A) Representative FACS data (left) and statistical analysis (right) of the surface phenotype of imDCs and TAA-pulsed mDCs. (B) CD8 ${ }^{+}$T-cell population (left) and the levels of IFN- $\gamma$ and IL-4 (right) were assessed from the co-culture of autologous T cells with TAApulsed or Ag-unpulsed mDCs at a 10:1 ratio in the presence of IL-7 (Peprotech). Activated T cells were restimulated three times every 7-8 days with a same set of TAA-pulsed DCs at the same ratio as described in the Supplementary Method. (C) From the activated T cells, the CTL was assessed with MHC-matched HepG2 target cells at different effector/target (E/T) ratios as described in the Supplementary Method. Data are presented as mean \pm s.d. of nine samples pooled from three individual experiments. ${ }^{*} P<0.05$ and ${ }^{\star *} P<0.01$ compared with control CTLs prepared by stimulation of T cells with Ag-unpulsed mDCs, Student's t-test.

\section{Table 2. Quality control of 12 DC vaccines}

\begin{tabular}{|c|c|c|c|c|c|c|c|c|c|c|c|c|}
\hline Patient no. & 01 & 02 & 03 & 04 & 05 & 06 & 07 & 08 & 09 & 10 & 11 & 12 \\
\hline Sterility & Pass & Pass & Pass & Pass & Pass & Pass & Pass & Pass & Pass & Pass & Pass & Pass \\
\hline \multicolumn{13}{|l|}{ Mycoplasma } \\
\hline $\begin{array}{l}\text { I (PCR) } \\
\text { II (Direct culture) }\end{array}$ & $\begin{array}{l}\text { Pass } \\
\text { Pass }\end{array}$ & $\begin{array}{l}\text { Pass } \\
\text { Pass }\end{array}$ & $\begin{array}{l}\text { Pass } \\
\text { Pass }\end{array}$ & $\begin{array}{l}\text { Pass } \\
\text { Pass }\end{array}$ & $\begin{array}{l}\text { Pass } \\
\text { Pass }\end{array}$ & $\begin{array}{l}\text { Pass } \\
\text { Pass }\end{array}$ & $\begin{array}{l}\text { Pass } \\
\text { Pass }\end{array}$ & $\begin{array}{l}\text { Pass } \\
\text { Pass }\end{array}$ & $\begin{array}{l}\text { Pass } \\
\text { Pass }\end{array}$ & $\begin{array}{l}\text { Pass } \\
\text { Pass }\end{array}$ & $\begin{array}{l}\text { Pass } \\
\text { Pass }\end{array}$ & $\begin{array}{l}\text { Pass } \\
\text { Pass }\end{array}$ \\
\hline Endotoxin $\left(<10 \mathrm{EU} \mathrm{ml}^{-1}\right)$ & Pass & Pass & Pass & Pass & Pass & Pass & Pass & Pass & Pass & Pass & Pass & Pass \\
\hline Viability (\%) ${ }^{a}$ & 83.1 & 85.7 & 75.4 & 77.2 & 86.8 & 80.8 & 88.2 & 88.2 & 86.1 & 76.5 & 89.8 & 78.6 \\
\hline \multicolumn{13}{|l|}{ Phenotype identification } \\
\hline Size and granularity $(\%)^{b}$ & 85.1 & 90.9 & 93.6 & 93.8 & 96.4 & 93.7 & 97.8 & 96.6 & 84.4 & 89.1 & 91.5 & 92.2 \\
\hline $\begin{array}{l}\text { Cell surface phenotype }(\%)^{c} \\
\text { HLA-DR } \\
\text { HLA-ABC } \\
\text { CD86 } \\
\text { CD80 } \\
\text { CD40 } \\
\text { CD83 }\end{array}$ & $\begin{array}{l}96.2 \\
99.4 \\
92.3 \\
84.8 \\
87.2 \\
54.3\end{array}$ & $\begin{array}{l}99.7 \\
99.1 \\
98.5 \\
97.8 \\
84.8 \\
46.8\end{array}$ & $\begin{array}{l}98.7 \\
99.6 \\
96.3 \\
86.1 \\
82.9 \\
15.7\end{array}$ & $\begin{array}{l}98.1 \\
95.1 \\
93.4 \\
85.5 \\
84.7 \\
13.8\end{array}$ & $\begin{array}{l}98.1 \\
98.9 \\
94.6 \\
84.0 \\
81.0 \\
14.5\end{array}$ & $\begin{array}{l}95.2 \\
99.3 \\
98.9 \\
92.8 \\
89.7 \\
82.1\end{array}$ & $\begin{array}{l}96.9 \\
99.8 \\
99.7 \\
96.3 \\
93.7 \\
96.0\end{array}$ & $\begin{array}{l}96.0 \\
99.2 \\
98.8 \\
94.6 \\
84.7 \\
86.9\end{array}$ & $\begin{array}{l}89.6 \\
99.2 \\
96.6 \\
93.7 \\
85.8 \\
65.6\end{array}$ & $\begin{array}{l}95.4 \\
99.5 \\
98.8 \\
86.6 \\
87.5 \\
61.2\end{array}$ & $\begin{array}{l}95.6 \\
99.4 \\
99.2 \\
94.7 \\
92.4 \\
86.8\end{array}$ & $\begin{array}{l}91.7 \\
98.8 \\
98.2 \\
87.9 \\
84.3 \\
79.4\end{array}$ \\
\hline \multicolumn{13}{|c|}{ Purity test (lineage negativity $\%)^{c}$} \\
\hline $\begin{array}{l}\text { CD14 } \\
\text { CD19 }\end{array}$ & $\begin{array}{l}1.5 \\
1.6\end{array}$ & $\begin{array}{l}2.0 \\
0.6\end{array}$ & $\begin{array}{l}8.4 \\
0.9\end{array}$ & $\begin{array}{l}0.3 \\
0.1\end{array}$ & $\begin{array}{l}0.5 \\
0.3\end{array}$ & $\begin{array}{l}0.6 \\
1.9\end{array}$ & $\begin{array}{l}1.0 \\
0.4\end{array}$ & $\begin{array}{l}1.9 \\
0.5\end{array}$ & $\begin{array}{l}1.4 \\
0.8\end{array}$ & $\begin{array}{l}1.1 \\
0.2\end{array}$ & $\begin{array}{l}1.2 \\
0.6\end{array}$ & $\begin{array}{l}1.3 \\
0.5\end{array}$ \\
\hline
\end{tabular}

menorrhagia (one event in one patient (no. 11)), none of which were assessed as drug-related adverse reactions and thus did not stop the DC vaccine treatment.
DC vaccination augmented TAA-reactive T-cell response. Eleven of 12 patients (91.6\%; all patients except for no. 11) showed an increase in TAA-reactive lymphocyte population after DC 
Table 3. Adverse events

\section{All adverse events ${ }^{a} \quad \| \quad$ Adverse drug reactions}

\begin{tabular}{|c|c|c|c|c|}
\hline & Any grade & Grades 3 or 4 & Any grade & Grades 3 or 4 \\
\hline Overall incidence & $12(100)$ & $4(33)$ & $12(100)$ & 0 \\
\hline \multicolumn{5}{|c|}{ Application site disorders } \\
\hline Injection site pain & $12(100)$ & 0 & $12(100)$ & 0 \\
\hline \multicolumn{5}{|c|}{ Body as a whole-general disorders } \\
\hline Ascites & $1(8)$ & 0 & 0 & 0 \\
\hline Fatigue & $4(33)$ & 0 & $4(33)$ & 0 \\
\hline Fever & $8(67)$ & 0 & $8(67)$ & 0 \\
\hline Pain & $7(58)$ & 0 & $6(50)$ & 0 \\
\hline Pain neck/shoulder & $1(8)$ & 0 & 0 & 0 \\
\hline Sweating increased & $1(8)$ & 0 & $1(8)$ & 0 \\
\hline Weakness & $1(8)$ & 0 & 0 & 0 \\
\hline \multicolumn{5}{|c|}{ Central and peripheral nervous system disorders } \\
\hline Headache & $5(42)$ & 0 & $4(33)$ & 0 \\
\hline \multicolumn{5}{|c|}{ Gastro-intestinal system disorders } \\
\hline Hiccups & $1(8)$ & 0 & 0 & 0 \\
\hline Nausea & $1(8)$ & 0 & 0 & 0 \\
\hline
\end{tabular}

Hearing and vestibular disorders

\begin{tabular}{l} 
Tinnitus \\
\hline Platelet bleeding and clotting disorder
\end{tabular}

\begin{tabular}{|c|c|c|c|c|}
\hline Platelets count decreased & $9(75)$ & $1(8)$ & 0 & 0 \\
\hline \multicolumn{5}{|l|}{ Psychiatric disorders } \\
\hline Insomnia & $1(8)$ & 0 & 0 & 0 \\
\hline \multicolumn{5}{|l|}{ Reproductive disorders, female } \\
\hline Menorrhagia & 0 & $1(8)$ & 0 & 0 \\
\hline \multicolumn{5}{|l|}{ Red blood cell disorders } \\
\hline Haematocrit decreased & $5(42)$ & 0 & 0 & 0 \\
\hline Haemoglobin decreased & $6(50)$ & 0 & 0 & 0 \\
\hline RBC decreased & $5(42)$ & 0 & 0 & 0 \\
\hline \multicolumn{5}{|l|}{ Respiratory system disorders } \\
\hline Rhinitis & $1(8)$ & 0 & 0 & 0 \\
\hline Rhinorrhea & $2(17)$ & 0 & 0 & 0 \\
\hline \multicolumn{5}{|l|}{ Secondary terms - events } \\
\hline Brain metastases & 0 & $1(8)$ & 0 & 0 \\
\hline Hepatoma recurrence & 0 & $2(17)$ & 0 & 0 \\
\hline Lymph node metastases & 0 & $1(8)$ & 0 & 0 \\
\hline \multicolumn{5}{|c|}{ Musculoskeletal system disorders } \\
\hline Myalgia & $3(25)$ & 0 & $3(25)$ & 0 \\
\hline \multicolumn{5}{|l|}{ White cell and RES disorders } \\
\hline Eosinophil count decreased & $3(25)$ & 0 & 0 & 0 \\
\hline Eosinophil count increased & $5(42)$ & 0 & 0 & 0 \\
\hline Leukopenia & $8(67)$ & $1(8)^{\mathbf{b}}$ & 0 & 0 \\
\hline Lymphocytosis & $3(25)$ & 0 & 0 & 0 \\
\hline Lymphopenia & $1(8)$ & $1(8)^{b}$ & 0 & 0 \\
\hline Monocytosis & $9(75)$ & 0 & 0 & 0 \\
\hline Neutropenia & $7(58)$ & $1(8)^{\mathbf{b}}$ & 0 & 0 \\
\hline Neutrophil count increased & $2(17)$ & 0 & 0 & 0 \\
\hline White blood cell count increased & $1(8)$ & 0 & 0 & 0 \\
\hline
\end{tabular}

vaccination (Table 4). Each TAA showed comparable capacity to induce lymphocyte proliferation, and the TAA-reactive T-cell populations significantly increased in proportion to the number of repeated vaccinations except at week 24 (Figure 3A, upper). Particularly, it is worth noting that nine recurrence-free patients showed greater TAA-specific T-cell proliferation when compared with the three patients with recurrence after TAA-pulsed DC vaccinations (Figure 3A, lower). To examine the proportion of TAAresponsive effecter $\mathrm{T}$ cells in the proliferated $\mathrm{T}$-cell populations, we performed IFN $-\gamma^{+}$ELISPOT assay, and the results were summarised in Supplementary Table S1. As shown in Figure 3B, number of IFN$\gamma^{+}$ELISPOT increased with repeated DC vaccinations (Figure 3B, upper). Among the TAAs, AFP showed the highest reactivity, while GPC-3 antigen was moderate in its capacity to induce effecter T-cell responses. The ELISPOT assay after DC vaccinations also showed that the average number of effecter $\mathrm{T}$ cells was larger in nine recurrent-free patients than in three recurrent patients (Figure 3B, lower). The changes in serum levels of IL-10, TGF- $\beta$, and VEGF are provided in Table 4 . There were not any clear tendencies for changes in serum cytokine levels for any patient. Serum levels of IL-10, TGF- 


\begin{tabular}{|c|c|c|c|c|c|c|c|c|c|c|}
\hline \multirow[b]{2}{*}{ Patient no. } & \multirow[b]{2}{*}{$\begin{array}{l}\text { Lymphocyte } \\
\text { proliferation }^{\mathrm{a}}\end{array}$} & \multirow[b]{2}{*}{$\begin{array}{l}\text { IL-10 } \\
\text { change } \\
(\%)^{\mathrm{b}}\end{array}$} & \multirow[b]{2}{*}{$\begin{array}{l}\text { TGF- } \beta \\
\text { change } \\
(\%)^{\mathrm{b}}\end{array}$} & \multirow[b]{2}{*}{$\begin{array}{l}\text { VEGF } \\
\text { change } \\
(\%)^{\mathrm{b}}\end{array}$} & \multirow[b]{2}{*}{$\begin{array}{c}\text { AFP } \\
\text { change } \\
(\%)^{\mathrm{b}}\end{array}$} & \multirow[b]{2}{*}{$\begin{array}{l}\text { PIVKA-II } \\
\text { change } \\
(\%)^{\mathrm{b}}\end{array}$} & \multicolumn{2}{|c|}{$\begin{array}{c}\text { Recurrence TTP } \\
\text { (day) }\end{array}$} & \multicolumn{2}{|c|}{$\begin{array}{l}\text { Death }^{c} \\
\text { (day) }\end{array}$} \\
\hline & & & & & & & SP & FU & SP & FU \\
\hline 01 & Positive & 14.7 & 4.1 & 4.0 & -23.0 & 7.7 & No & No & No & No \\
\hline 02 & Positive & -16.8 & -16.6 & -6.8 & -21.1 & 31.6 & No & No & No & No \\
\hline 03 & Positive & 26.2 & -15.8 & -3.2 & -47.5 & 52.6 & No & Yes $(294 / 217)$ & No & Yes $(878 / 801)$ \\
\hline 04 & Positive & -20.9 & 35.2 & 6.9 & 8.6 & 0.0 & No & Yes (1075/963) & No & No \\
\hline 05 & Positive & 98.1 & 3.5 & -2.1 & 25.9 & 12.5 & No & Yes $(917 / 805)$ & No & No \\
\hline 06 & Positive & -13.3 & 59.2 & 36.8 & -21.5 & 0.0 & No & No & No & No \\
\hline 07 & Positive & -22.4 & -32.3 & 42.3 & 63.6 & 37.0 & Yes (134/61) & - & No & Yes $(340 / 267)$ \\
\hline $08^{d}$ & Positive & -23.7 & 49.5 & -17.6 & -10.3 & -28.6 & No & No & No & No \\
\hline $09^{d}$ & Positive & 70.8 & -66.8 & -5.6 & 569.1 & 1619.6 & Yes (205/91) & - & No & Yes (312/198) \\
\hline 10 & Positive & 8.3 & 8.6 & -36.8 & -30.8 & 13.3 & No & Yes $(1226 / 1037)$ & No & No \\
\hline 11 & Negative & -12.4 & -7.5 & 226.0 & -16.7 & 44.4 & No & No & No & No \\
\hline 12 & Positive & 26.0 & 20.7 & -24.0 & 25.0 & 122.2 & Yes (259/139) & - & No & Yes $(783 / 663)$ \\
\hline \multicolumn{11}{|c|}{ 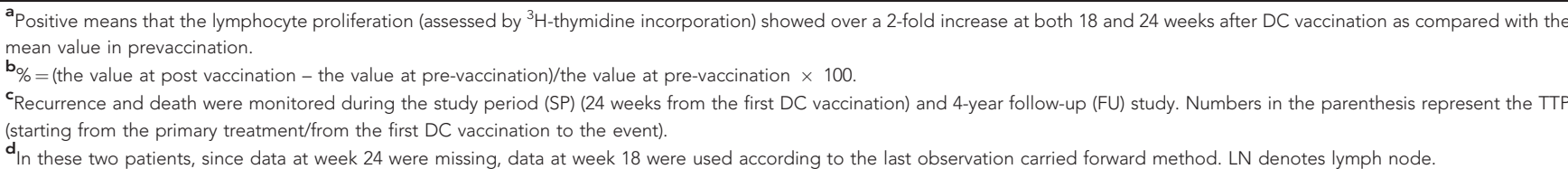 } \\
\hline
\end{tabular}

$\beta$, and VEGF between baseline and week 24 were not significantly different (all $P>0.05$ by Wilcoxon signed-rank test). We could not see any discernible correlation between positivity for lymphocyte proliferation tests and changes in immunosuppressive cytokine levels (all $P>0.05$ by Wilcoxon signed-rank test).

Clinical efficacy evaluation. Clinical outcomes are also summarised in Table 4. Tumour assessments were performed using dynamic CT or MRI according to RECIST criteria. Nine of 12 patients were free of recurrence up to 24 weeks after DC vaccination. Representative CT and MRI results of two recurrence-free patients are shown in Figure 4. Three patients experienced tumour recurrence; cumulative recurrence rates at weeks 18 and 24 were $16.7 \%$ ( 2 of 12 ) and $25 \%$ ( 3 of 12), respectively. Tumour recurrences occurred at lymph nodes (one patient) or liver (two patients). All three patients with tumour recurrence had prior history of HCC treatment including TACE and PEI. Two patients died during the study period, and the mortalities were related to progression of the recurred tumour. The median levels of serum AFP were comparable between baseline and week 24 (6.6 (range, 2.6-5470) vs 5.6 (range, 1.8$36600) \mathrm{ng} \mathrm{ml}^{-1} ; P=0.91$ by Wilcoxon signed-rank test). The median serum level of PIVKA-II increased during the study period (18.5 (range, 9-2040) vs 21.5 (range, 13-35080) $\mathrm{nAU} \mathrm{ml}^{-1}$; $P=0.02$ by Wilcoxon signed-rank test). There was no significant change in patient performance status according to the Kornofsky scale during the treatment period (data not shown).

In the 4-year follow-up study, an additional 4 (total 7, 58.3\%) of 12 patients showed recurrence and 2 more patients (total 4, 33.3\%) died of recurrent cancer, while 27 (87.1\%) of 31 control patients who were matched by treatment modality from the historical control group showed recurrence during the same period. The patient composition and baseline characteristics of the control patients were summarised in Table 5. The median time of TTP was 38.4 months in the DC-vaccination group and 10.8 months in the control group (hazard ratio (HR) with immunotherapy, $0.41 ; 95 \%$ confidence interval (CI), $0.18-0.95 ; P=0.0031$ by log-rank test; Figure 5). With respect to recurrence during the entire study and follow-up period, 5-year RFS rates were $41.7 \%$ for patients who received DC vaccine therapy $(n=12)$, while $12.9 \%$ for the historical controls ( $n=31$; Figure 5). In addition, the 1-, 2-, and 5 -year cumulative RFS rates were $75 \%, 69 \%$, and $41.7 \%$, respectively, for patients who received DC vaccine therapy $(n=12)$, compared with $58 \%, 19.3 \%$, and $16.1 \%$, respectively, for the historical controls (Figure 5).

\section{DISCUSSION}

HCC development and progression are related to chronic inflammation (Grivennikov et al, 2010). Once tumours are established, mutual interactions between tumours and immune cells present during inflammation may provide conditions favourable for tumour cell survival (Ungefroren et al, 2011). Immune suppressor cells (e.g., regulatory $\mathrm{T}$ cells, myeloid-derived suppressive cells, or tumourassociated macrophages) facilitate tumour immune evasion (Zamarron and Chen, 2011). Natural tumour-infiltrating lymphocytes are incompletely activated, proliferate little, and fail to eradicate tumours (Korangy et al, 2010). DCs have an essential role in antitumour immunogenicity, particularly in the proliferation of tumourspecific CTL. However, the number and function of DCs in tumour patients are suppressed or dysfunctional. Thus, ex vivo-generated DC vaccine therapy is expected to produce an appropriate anti-tumour immune response.

In the present study, a number of strategies were applied to enhance the efficacy of DC vaccine. First, autologous DC vaccines were prepared by pulsing monocyte-derived DCs with three common HCC TAAs (AFP, MAGE-1, and GPC-3) in order to account for the heterogeneity of HCC based on the tissue array results from 412 HCC patients in Korea (unpublished data). Second, CTP-fused TAAs were used to facilitate CTP-mediated antigen delivery into the cytoplasm of DCs (Kim et al, 2006), leading to better induction of TAA-specific CTLs. Third, topical TLR-7 agonist (imiquimode), which is known to facilitate DC migration to the regional lymph node (Prins et al, 2006), was 


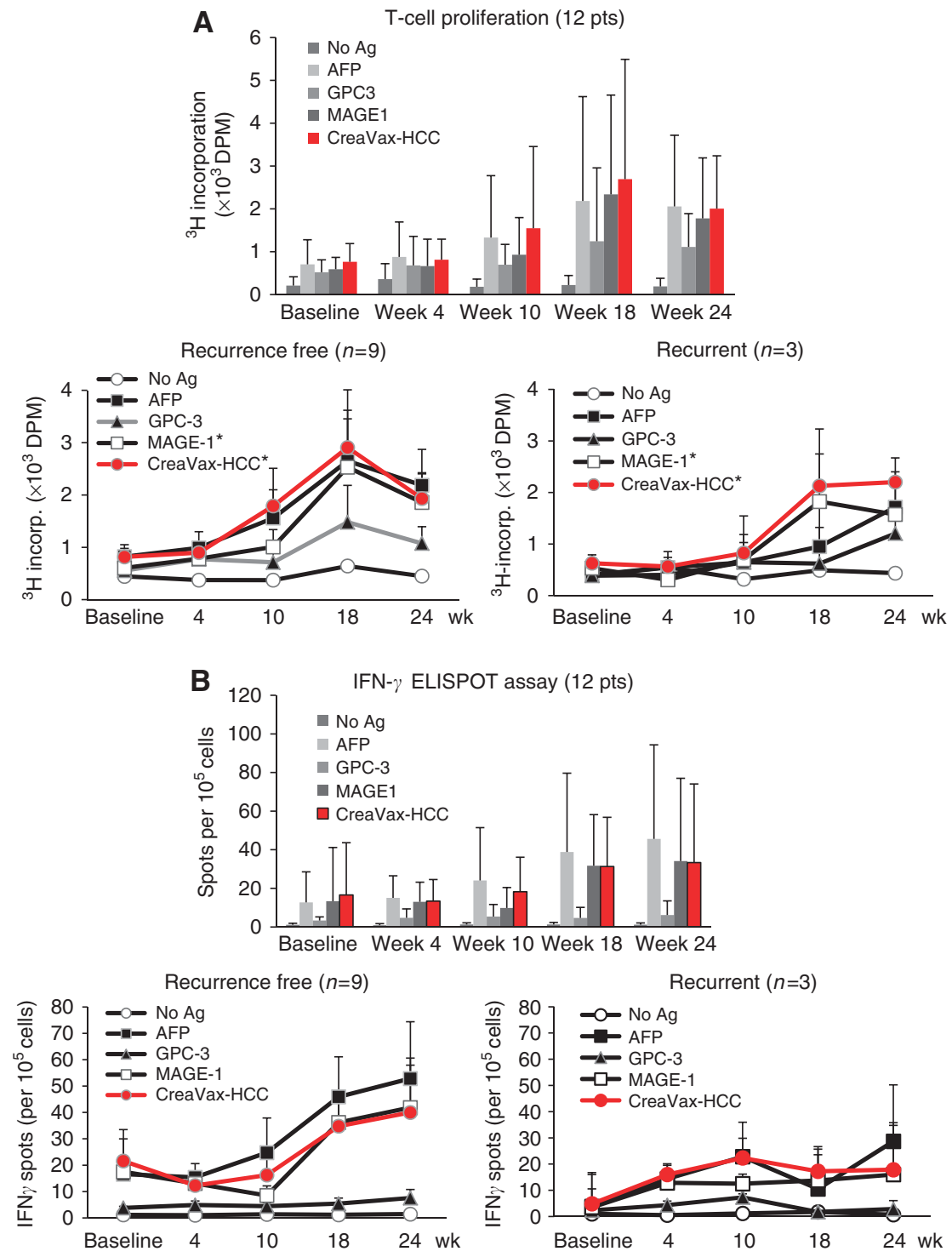

Figure 3. Immunological analysis after DC vaccination. (A) Antigen-specific lymphocyte proliferation assay was performed during and after DC vaccinations using the autologous PBMCs obtained from 12 patients (upper), and the results were further analysed in recurrence-free patients (lower left) and recurrent patients (lower right). The proliferation was determined by ${ }^{3} \mathrm{H}$-thymidine incorporation (dpm) using a liquid scintillation counter. Data are presented as mean \pm s.e., ${ }^{*} P<0.05$. (B) ELISPOT assay was performed with the PBMCs obtained from each patient at the indicated time points after the start of DC vaccination. The results from all (12) patients (upper), the nine recurrence-free patients (lower left) and the three recurrent patients (lower right) are presented as mean \pm s.e.

applied around the injection site of DC vaccines to induce a synergistic effect with DC vaccination. Fourth, instead of epitope peptides, recombinant proteins of TAAs were used to overcome the HLA restriction. Fifth, patients who had no evidence of residual HCC after primary treatment were included in this study in order to minimise tumour-mediated immune suppression (Beyer and Schultze, 2006; Diaz-Montero et al, 2009). Sixth, DC vaccines were injected s.c. into the thigh near the inguinal lymph nodes rather than intravenously (i.v.) to increase the number of DCs reaching regional lymph nodes (Lappin et al, 1999; Okada et al, 2001). Dendritic cell vaccines are injected either intradermally (i.d.), s.c., i.v., or sometimes intratumourally depending on the tumour types and/or the study protocols designed on the basis of the preclinical study. The cases using i.d. injection were about twice as many as those using s.c. route among the DC vaccine trials registered on the NIH clinical trials site (https://clinicaltrials.gov). In our preclinical study, however, we found that there was no significant difference in efficacy between the i.d. and s.c. injections. Thus, in the present clinical study, we delivered DC vaccines s.c.
In this phase I/IIa trial, we investigated the safety and efficacy of DC vaccines using autologous TAA-pulsed DCs in 12 patients with HCC after surgical resection or loco-regional therapy. Adverse drug reactions including injection site pain, fever, and myalgia occurred in all patients. However, there was no serious adverse drug reaction limiting DC vaccination, and all 12 patients tolerated the scheduled six injections well. Nine of 12 patients remained tumour free up to 24 weeks after DC vaccination, while three patients experienced tumour recurrence. The majority of patients showed enhanced TAA-specific cellular immune response after DC vaccination, presumably leading to effective inhibition of tumour recurrence after primary treatment of HCC. Recurrence-free patients exhibited relatively stronger anti-tumour immune responses than the patients who developed recurrent tumour after DC vaccination, as evidenced by lymphocyte proliferation and IFN- $\gamma$ ELISPOT assays (Figure 3). The degree of immunologic response appears to have clinical significance as it seems to correlate with the clinical efficacy results (i.e., tumour recurrence in Table 4). The 4-year follow-up study clearly showed that RFS rates 
AN-HCC-004

\begin{tabular}{|c|}
\hline Medical treatment \\
06.10.09 1st TACE \\
07.01.04 2nd TACE \\
07.01.05 RFA \\
${ }^{*}$ yy-mm-dd
\end{tabular}

Recurrence free

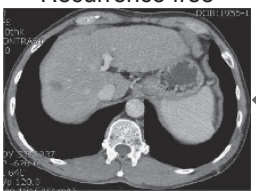

[2010.03.15 CT]
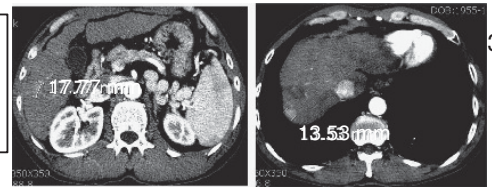

[2009.06.23 CT]

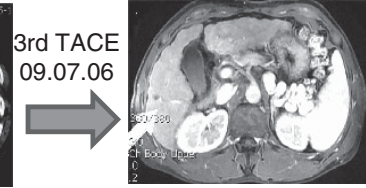

[2009.09.16 MRI]

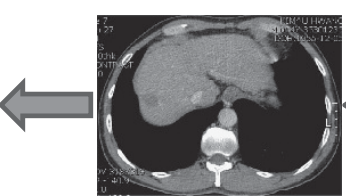

[2009.12.22 CT]

AN-HCC-006

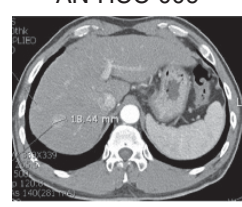

[2009.06.15 CT]

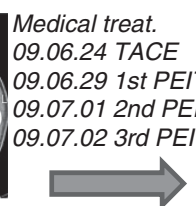

9.07.01 2nd PEIT 07.02 3rd PEIT$$
\text { (20) }
$$

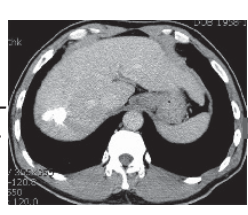

[2009.09.29 CT]

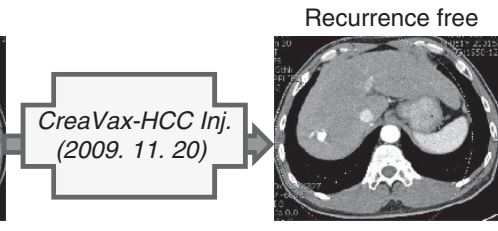

[2010.04.13 CT]

Figure 4. CT and MRI scan data of two representative patients (pt4 and pt6) before and after one cycle of antigen-pulsed DC vaccination. Treatment records of each patient are summarised.

\section{Table 5. Patient compositions and baseline characteristics of historical control group}

\begin{tabular}{|c|c|c|c|c|}
\hline & \multicolumn{2}{|c|}{ DC vaccinated $(n=12)$} & \multicolumn{2}{|c|}{ Histological control $(n=31)^{a}$} \\
\hline Age, years (median, range) & 57 & $45-71$ & 58 & $33-73$ \\
\hline Gender $(N, \%)$, male, female & M10 (83.3\%) & F2 (12.7\%) & M25 (80.6\%) & F6 (19.4\%) \\
\hline HCC history ${ }^{\mathbf{b}}(N, \%)$, new/recurrent & New 6 (50\%) & Recurrent 6 (50\%) & New 18 (58\%) & Recurrent 13 (42\%) \\
\hline \multicolumn{5}{|l|}{ Primary treatment } \\
\hline $\begin{array}{l}\text { Surgery }(N, \%) \\
\text { RFA }(N, \%) \\
\text { TACE }(N, \%) \\
\text { PEIT }(N, \%) \\
\text { Total }(N, \%)\end{array}$ & $\begin{array}{r}4 \\
4 \\
2 \\
2 \\
12\end{array}$ & $\begin{array}{c}33.3 \% \\
33.3 \% \\
16.7 \% \\
16.7 \% \\
100.0 \%\end{array}$ & $\begin{array}{r}11 \\
10 \\
6 \\
4 \\
31\end{array}$ & $\begin{array}{c}35.5 \% \\
32.3 \% \\
19.3 \% \\
12.9 \% \\
100.0 \%\end{array}$ \\
\hline $\operatorname{Recurrence}^{c}(N, \%)$ & $7 / 12$ & $58.3 \%$ & $27 / 31$ & $87.1 \%$ \\
\hline Baseline characteristics & \multicolumn{2}{|c|}{ DC vaccinated $(n=12)$} & Historical control $(n=31)$ & $P$ value ${ }^{d}$ \\
\hline DM patient, $N(\%)$ & \multicolumn{2}{|c|}{$10(83.3)$} & $27(87.1)$ & 1 \\
\hline AST, $I U I^{-1}$ & \multicolumn{2}{|c|}{$43.5 \pm 10.4$} & $47.4 \pm 40.3$ & 0.183 \\
\hline$A L T,|U|^{-1}$ & \multicolumn{2}{|c|}{$46.2 \pm 21.0$} & $44.4 \pm 32.0$ & 0.478 \\
\hline Albumin, $\mathrm{gdl}^{-1}$ & \multicolumn{2}{|c|}{$3.88 \pm 0.39$} & $4.03 \pm 0.43$ & 0.183 \\
\hline Total bilirubin, $\mathrm{mg} \mathrm{dl}^{-1}$ & \multicolumn{2}{|c|}{$0.93 \pm 0.43$} & $0.97 \pm 0.59$ & 0.989 \\
\hline PT INR & \multicolumn{2}{|c|}{$1.15 \pm 0.07$} & $1.19 \pm 0.29$ & 0.64 \\
\hline Platelet, $\times\left. 10^{3} \mu\right|^{-1}$ & \multicolumn{2}{|c|}{$133.3 \pm 35.8$} & $132.2 \pm 43.3$ & 0.942 \\
\hline Creatinine, $\mathrm{mg} \mathrm{dl}^{-1}$ & \multicolumn{2}{|c|}{$0.92 \pm 0.16$} & $0.96 \pm 0.24$ & 0.698 \\
\hline$A F P, n g m l^{-1}$ & \multicolumn{2}{|c|}{$7.3(4.6,11.4)$} & $7.4(3.8,24.0)$ & 0.602 \\
\hline Tumour size, $\mathrm{cm}$ & \multicolumn{2}{|c|}{$1.8(1.0,2.2)$} & $2.2(1.3,3.5)$ & 0.121 \\
\hline Tumour number & \multicolumn{2}{|c|}{$1.67 \pm 0.78$} & $1.52 \pm 1.26$ & 0.243 \\
\hline $\begin{array}{l}\text { Tumour stage } \\
\text { Stage I } \\
\text { Stage II } \\
\text { Stage IIIA }\end{array}$ & \multicolumn{2}{|c|}{$\begin{array}{l}8(66.7) \\
2(16.7) \\
2(16.7)\end{array}$} & $\begin{array}{c}24(77.4) \\
5(16.1) \\
2(6.5)\end{array}$ & 0.544 \\
\hline \multicolumn{5}{|c|}{ 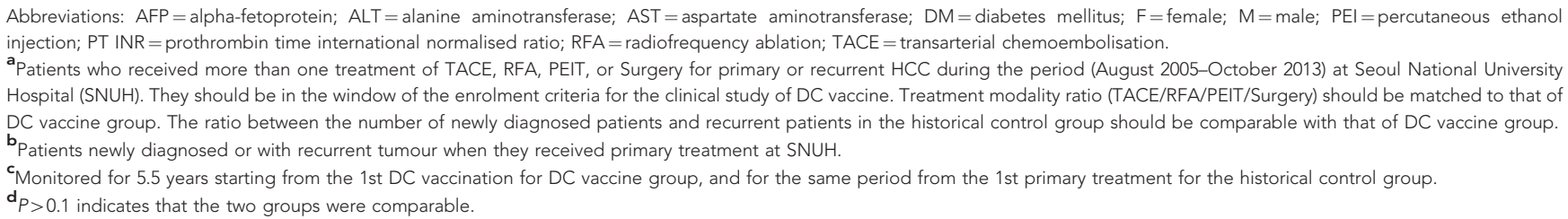 } \\
\hline
\end{tabular}




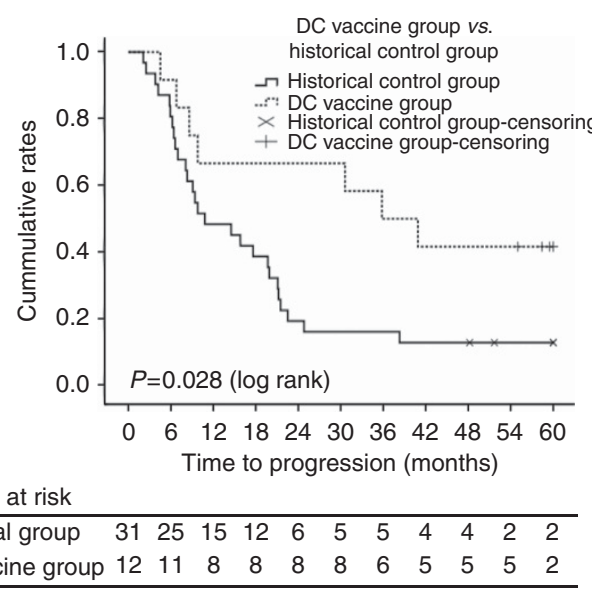

Figure 5. TTP and RFS (starting from primary treatments rather than baseline radiographic tumour assessments) of patients treated with DC vaccine during the trial period and 4-year follow-up study in comparison with historical controls $(n=31)$. The composition of 31 patients with HCC for historical control group was summarised in Table 5. A statistically significant difference in survival was noted $(P<0.05)$.

were significantly improved in DC vaccinated group as compared with historical control group. With these encouraging results, further clinical trials were designed and currently we are awaiting results from the phase II trial.

We defined TD instead of maximum TD (MTD), because most HCC patients have cytopenias, and thus repeated leukapheresis may not be feasible. We found that $5 \times 10^{7}$ cells per injection was well tolerated as revealed in our phase I/II study of DC vaccine in renal cell carcinoma (Kim et al, 2007), thus this dose was designated as TD. The dosages of the DC-based cancer vaccines registered on the NIH website https://clinicaltrials.gov are in the range of $1 \times 10^{6}$ and $1 \times 10^{8}$, and mostly $1 \sim 3 \times 10^{7}$ cells per injection. The TD we used $\left(5 \times 10^{7}\right)$ was slightly higher than the popular window, but was well tolerated in patients with no drugrelated G3/G4 toxicity as shown in Table 3.

Glypican-3 showed very weak immunogenicity in comparison with AFP or MAGE-1 (Figure 3), probably because the more immunogenic C-terminal end of GPC-3 was excluded in the recombinant GPC-3 protein due to its weak solubility. In the lymphocyte proliferation assay, 11 patients showed positive results. Interestingly, lymphocyte proliferation showed a decreasing trend after week 18 (Figure 3A). It is well established that frequent vaccinations in a short period can induce antigen-specific T-cell inactivation, so-called 'activation-induced cell death,' rather than further activation (Hermans et al, 2000). In order to prolong antitumour immunity, the vaccination schedule might need to be altered to include additional boosting and/or less-frequent injection in subsequent clinical studies. Collectively, modification of (i) TAAs (especially C-terminal included GPC-3 protein) and (ii) vaccination schedule (e.g., additional boosting after week 18 and less-frequent vaccination in the early period) might be necessary to enhance the efficacy of DC vaccines in future phase II and III studies.

\section{CONCLUSION}

Summarizing our findings, this phase I/IIa study confirmed that DC vaccine pulsed by three HCC-specific TAAs were successfully generated and well tolerated at a dose of $5 \times 10^{7}$ cells per injection without dose-limiting severe adverse drug reactions. The majority of patients showed evidence of induced HCC-specific immune responses. Preliminary efficacy results were encouraging, but still speculative for a limited number of patients. Thus, additional phase II and III studies may be warranted to evaluate the clinical efficacy of DC vaccines in HCC patients.

\section{ACKNOWLEDGEMENTS}

This study was supported by a Bio New Drug grant (A085033) of the Korean Health Technology R\&D Project, Ministry of Health \& Welfare, Republic of Korea.

CONFLICT OF INTEREST

YL, MKHeo, and J-SS are CreaGene Inc. employees. Y-SB has been a consultant for JW CreaGene Inc. All remaining authors have declared no conflicts of interest.

\section{REFERENCES}

Banchereau J, Steinman RM (1998) Dendritic cells and the control of immunity. Nature 392(6673): 245-252.

Beyer M, Schultze JL (2006) Regulatory T cells in cancer. Blood 108(3): 804-811.

Bolondi L, Sofia S, Siringo S, Gaiani S, Casali A, Zironi G, Piscaglia F, Gramantieri L, Zanetti M, Sherman M (2001) Surveillance programme of cirrhotic patients for early diagnosis and treatment of hepatocellular carcinoma: a cost effectiveness analysis. Gut 48(2): 251-259.

Britten CM, Janetzki S, Butterfield LH, Ferrari G, Gouttefangeas C, Huber C, Kalos M, Levitsky HI, Maecker HT, Melief CJ, O’Donnell-Tormey J, Odunsi K, Old LJ, Ottenhoff TH, Ottensmeier C, Pawelec G, Roederer M, Roep BO, Romero P, van der Burg SH, Walter S, Hoos A, Davis MM (2012) T cell assays and MIATA: the essential minimum for maximum impact. Immunity 37(1): 1-2.

Bruix J, Sherman M. American Association for the Study of Liver Diseases (2011) Management of hepatocellular carcinoma: an update. Hepatology 53(3): 1020-1022.

Butterfield LH, Ribas A, Dissette VB, Lee Y, Yang JQ, De la Rocha P, Duran SD, Hernandez J, Seja E, Potter DM, McBride WH, Finn R, Glaspy JA, Economou JS (2006) A phase I/II trial testing immunization of hepatocellular carcinoma patients with dendritic cells pulsed with four alpha-fetoprotein peptides. Clin Cancer Res 12(9): 2817-2825.

den Brok MH, Nierkens S, Figdor CG, Ruers TJ, Adema GJ (2005) Dendritic cells: tools and targets for antitumor vaccination. Expert Rev Vaccines 4(5): 699-710.

Diaz-Montero CM, Salem ML, Nishimura MI, Garrett-Mayer E, Cole DJ, Montero AJ (2009) Increased circulating myeloid-derived suppressor cells correlate with clinical cancer stage, metastatic tumor burden, and doxorubicin-cyclophosphamide chemotherapy. Cancer Immunol Immunother 58(1): 49-59.

European Association for The Study of The Liver, European Organisation for Research Treatment of Cancer (2012) EASL-EORTC clinical practice guidelines: management of hepatocellular carcinoma. J Hepatol 56(4): 908-943.

Greene FL. American Joint Committee on Cancer, American Cancer Society (2002) AJCC Cancer Staging Manual, 6th edn. Springer-Verlag: New York.

Grivennikov SI, Greten FR, Karin M (2010) Immunity, inflammation, and cancer. Cell 140(6): 883-899.

Hermans IF, Ritchie DS, Yang J, Roberts JM, Ronchese F (2000) CD8 + T cell-dependent elimination of dendritic cells in vivo limits the induction of antitumor immunity. J Immunol 164(6): 3095-3101.

Holtl L, Rieser C, Papesh C, Ramoner R, Herold M, Klocker H, Radmayr C, Stenzl A, Bartsch G, Thurnher M (1999) Cellular and humoral immune responses in patients with metastatic renal cell carcinoma after vaccination with antigen pulsed dendritic cells. J Urol 161(3): 777-782. 
Kim D, Jeon C, Kim JH, Kim MS, Yoon CH, Choi IS, Kim SH, Bae YS (2006) Cytoplasmic transduction peptide (CTP): new approach for the delivery of biomolecules into cytoplasm in vitro and in vivo. Exp Cell Res 312(8): 1277-1288.

Kim JH, Lee Y, Bae YS, Kim WS, Kim K, Im HY, Kang WK, Park K, Choi HY, Lee HM, Baek SY, Lee H, Doh H, Kim BM, Kim CY, Jeon C, Jung CW (2007) Phase I/II study of immunotherapy using autologous tumor lysatepulsed dendritic cells in patients with metastatic renal cell carcinoma. Clin Immunol 125(3): 257-267.

Korangy F, Hochst B, Manns MP, Greten TF (2010) Immune responses in hepatocellular carcinoma. Dig Dis 28(1): 150-154.

Lai EC, Fan ST, Lo CM, Chu KM, Liu CL, Wong J (1995) Hepatic resection for hepatocellular carcinoma. An audit of 343 patients. Ann Surg 221(3): 291-298.

Lappin MB, Weiss JM, Delattre V, Mai B, Dittmar H, Maier C, Manke K, Grabbe S, Martin S, Simon JC (1999) Analysis of mouse dendritic cell migration in vivo upon subcutaneous and intravenous injection. Immunology 98(2): 181-188.

Lee WC, Wang HC, Hung CF, Huang PF, Lia CR, Chen MF (2005) Vaccination of advanced hepatocellular carcinoma patients with tumor lysate-pulsed dendritic cells: a clinical trial. J Immunother 28(5): 496-504.

Nestle FO, Alijagic S, Gilliet M, Sun Y, Grabbe S, Dummer R, Burg G, Schadendorf D (1998) Vaccination of melanoma patients with peptide- or tumor lysate-pulsed dendritic cells. Nat Med 4(3): 328-332.

Okada N, Tsujino M, Hagiwara Y, Tada A, Tamura Y, Mori K, Saito T, Nakagawa S, Mayumi T, Fujita T, Yamamoto A (2001) Administration route-dependent vaccine efficiency of murine dendritic cells pulsed with antigens. Br J Cancer 84(11): 1564-1570.

Palmer DH, Midgley RS, Mirza N, Torr EE, Ahmed F, Steele JC, Steven NM, Kerr DJ, Young LS, Adams DH (2009) A phase II study of adoptive immunotherapy using dendritic cells pulsed with tumor lysate in patients with hepatocellular carcinoma. Hepatology 49(1): 124-132.

Prins RM, Craft N, Bruhn KW, Khan-Farooqi H, Koya RC, Stripecke R, Miller JF, Liau LM (2006) The TLR-7 agonist, imiquimod, enhances dendritic cell survival and promotes tumor antigen-specific $\mathrm{T}$ cell priming: relation to central nervous system antitumor immunity. J Immunol 176(1): 157-164.

Samuel M, Chow PK, Chan Shih-Yen E, Machin D, Soo KC (2009) Neoadjuvant and adjuvant therapy for surgical resection of hepatocellular carcinoma. Cochrane Database Syst Rev (1): CD001199.

Schwartz JD, Schwartz M, Mandeli J, Sung M (2002) Neoadjuvant and adjuvant therapy for resectable hepatocellular carcinoma: review of the randomised clinical trials. Lancet Oncol 3(10): 593-603.

Small EJ, Fratesi P, Reese DM, Strang G, Laus R, Peshwa MV, Valone FH (2000) Immunotherapy of hormone-refractory prostate cancer with antigen-loaded dendritic cells. J Clin Oncol 18(23): 3894-3903.

Tada F, Abe M, Hirooka M, Ikeda Y, Hiasa Y, Lee Y, Jung NC, Lee WB, Lee HS, Bae YS, Onji M (2012) Phase I/II study of immunotherapy using tumor antigen-pulsed dendritic cells in patients with hepatocellular carcinoma. Int J Oncol 41(5): 1601-1609.

Ungefroren H, Sebens S, Seidl D, Lehnert H, Hass R (2011) Interaction of tumor cells with the microenvironment. Cell Commun Signal 9: 18.

Verslype C, Rosmorduc O, Rougier P. ESMO Guidelines Working Group (2012) Hepatocellular carcinoma: ESMO-ESDO Clinical Practice Guidelines for diagnosis, treatment and follow-up. Ann Oncol 23(Suppl 7): vii41-vii48.

Yuen MF, Cheng CC, Lauder IJ, Lam SK, Ooi CG, Lai CL (2000) Early detection of hepatocellular carcinoma increases the chance of treatment: Hong Kong experience. Hepatology 31(2): 330-335.

Zamarron BF, Chen W (2011) Dual roles of immune cells and their factors in cancer development and progression. Int J Biol Sci 7(5): 651-658.

This work is published under the standard license to publish agreement. After 12 months the work will become freely available and the license terms will switch to a Creative Commons AttributionNonCommercial-Share Alike 4.0 Unported License.

Supplementary Information accompanies this paper on British Journal of Cancer website (http://www.nature.com/bjc) 